\title{
Modern problems of state regulation of operation of a large hydroelectric plants dams area
}

\author{
Natalia Mitina ${ }^{1}{ }^{*}$, Maxim Vashchenko ${ }^{1}$,Elena Shumakova $^{2}$ \\ ${ }^{1}$ Lomonosov Moscow State University, Lomonosovsky prosp. 27, korp. 4, 119991, Moscow, Russia \\ ${ }^{2}$ Institute of Water Problems RAS, Gubkina 3, 117333, Moscow, Russia
}

\begin{abstract}
The article is devoted to the problem of increasing the risk of accidents at the dam areas of a large power plant (HPP) and the surrounding area over time, and the need to take these risks into account during their operation. The purpose of the research is to introduce the concept of a dam area as an object of state regulation, to reveal the ways of development and legislative solution of the problem of safe operation of hydroelectric power plants and dam territories at the Federal level, and to develop recommendations for their state regulation. The paper shows the necessity and expediency of zoning the dam territory according to the degree of dynamic impact of the HPP on it in order to optimize the administrative and economic consequences of the operation of these objects.
\end{abstract}

\section{Introduction}

Hydroelectric power plants (HPP), dams and reservoirs, are strong and durable structures and can be operated for hundreds or thousands of years. All dams are in many ways unique in design, geological conditions of the base, operating conditions, and impacts on the surrounding areas, although successful design solutions are replicated. Dams, especially large ones, despite their reliability, are objects of high risk. Complete or partial destruction of the dam and complete or partial emptying of the reservoir is an extreme danger for the population and surrounding areas [1]. Although there is no unambiguous relationship between accidents at HPP their service life, based on the General laws of operation of complex objects, it is believed that the risk of an accident increases over the time. World experience shows that major accidents occurred in almost all countries - in the United States, France, Italy, India, Russia, China, and others. Causes of accidents can be very diverse:

- natural: seismic events, engineering-geological causes (landslide processes, special properties of soil bases), hydrological phenomena;

- natural and man-made: induced seismicity,

- technogenic: design features of dams, influence of their operation modes, etc.

*Corresponding author: natalia_mitina@mail.ru 
Currently, the Russian water management system includes about 65,000 objects that have been in operation for 30 years or more. Six of the world's eighteen major reservoirs and 14 hydroelectric power plants with a capacity of more than $1000 \mathrm{MW}$ are located in Russia. The most approximate estimates show that about 10 million people live in areas of potential flooding below the HPP.

The relevance of the study is due to several reasons. Among them:

- high potential risk of major accidents and man-made emergencies at HPP;

- gradual manifestation in the process of operation, the negative effect of the new factors associated with the mode of operation of the HPP that were not known at the time of design and construction or have not been addressed adequately, and these effects can spread far beyond the area directly hydroconstruction;

- at the moment, there are no rules in Russian legislation to regulate the operation of dam territories of HPP. The relevance of the study is due to several reasons. Among them:

- high potential risk of major accidents and man-made emergencies at hydraulic structures;

- gradual manifestation in the process of operation, the negative effect of the new factors associated with the mode of operation of the HPP that were not known at the time of design and construction or have not been addressed adequately, and these effects can spread far beyond the area directly hydro;

- at the moment, there are no rules in Russian legislation to regulate the operation of dam territories of large hydraulic structures.

In connection with the above, the aim was to consider the issues of regulating the operation of the dam territories of large HPP, including hydroelectric power plants (HPPs), and the main possible directions of state regulation. The subject of the study is the role of the state in regulating the regulations for the operation of dam territories of large HPP.

To achieve the research goal, the following tasks were set and solved:

- consider the possibility of introducing the concept of a dam territory as an object of state regulation;

- $\quad$ analyze the problems of exploitation of dam territories of large HPPs;

- identify and analyze areas of state policy in the field of regulating the operation of heavy engineering structures, HPPs and reservoirs (including current regulations);

- identify on the basis of foreign experience the main possible directions of state regulation of HPP operation regulations;

- review existing analogies in the current legislation of the Russian Federation of state regulation of the operation of special natural and man-made territories and assess the possibility of their application to the situation with the dynamic impact of the operating HPP;

- $\quad$ assess the possibility of ensuring the safety of the dam and surrounding areas within the normal technological regime of the HPP, existing regulatory documents;

- to reveal ways of development and legislative solution of the problem of safe operation of HPPs and dam territories at the Federal level;

- develop recommendations for state regulation.

\section{Material and Methods}

Research materials are the author's instrumental measurements of soil vibrations, buildings and structures near the Zhigulevskaya HPP dam in 1999-2017, the results of their statistical processing and analysis. The experience of the Togliatti municipality in reducing the negative dynamic impact of a working hydroelectric power plant on its territory was analyzed and summarized. Approaches to ensuring the safety of hydraulic structures and 
surrounding territories in Russia and abroad, as well as current regulatory and legislative acts, were analyzed. The method of analogies was used to apply approaches, techniques and methods for solving problems of various natural and man-made extreme situations from related fields of knowledge.

\section{Results and Discussion}

Based on the analysis of regulations, in particular the basic law "Federal law on the safety of hydraulic structures "dated 21.07.1997 N 117-FZ", it can be stated that the Federal law No. 117 regulates the safety of the HPP itself, but not the safety of the dam territory [2]. There are only possible analogies of state regulation of exploitation of special natural and natural-technogenic territories.

Special attention was paid to the issue of the dynamic impact of the operating HPP on the surrounding territories. As it was established relatively recently, the hydroelectric power plant is a source of vibrations that, under certain conditions, can be manifested at a great distance, far beyond the limits of the structure itself. These vibrations do not spread equally in all directions, but in accordance with the structure of the earth's crust, which is heterogeneous. Soil vibrations cause changes in the bearing properties of soils, resonant vibrations of buildings, and create a dynamic load that is not accounted for at the construction stage. Although the impact can be described as weak, its consequences over time of HPP operation are very destructive, that is, the area adjacent to the HPP dam requires state supervision and control within the framework of civil legislation (Table).

Table. Comparison of the effectiveness of the proposed approaches to solving the problem of large HPP state regulation.

\begin{tabular}{|l|l|l|}
\hline \multicolumn{1}{|c|}{ Approach } & \multicolumn{1}{|c|}{ Advantages } & \multicolumn{1}{c|}{ Disadvantages } \\
\hline Territorial approach & $\begin{array}{l}\text { Allows to differentiate the HPP } \\
\text { dam territory depending on the } \\
\text { intensity of negative impact. }\end{array}$ & $\begin{array}{l}\text { Now the boundaries of the territory } \\
\text { protected together with the } \\
\text { particularly important object are } \\
\text { defined by 500 m zone, where } \\
\text { control over the use of the territory } \\
\text { is carried out, although it is allowed } \\
\text { to stay population, equipment. }\end{array}$ \\
\hline $\begin{array}{l}\text { "Environmental } \\
\text { disaster zone" and }\end{array}$ & $\begin{array}{l}\text { The legislation contains such a } \\
\text { form of organizational mechanism } \\
\text { for environmental protection as the } \\
\text { declaration of the territory as an } \\
\text { Environmental disaster zone or } \\
\text { emergency zone. }\end{array}$ & $\begin{array}{l}\text { In practice, it is difficult to } \\
\text { determine the nature of changes: } \\
\text { whether they are stable or unstable, } \\
\text { have occurred or continue to occur. } \\
\text { The Institute of environmentally } \\
\text { disadvantaged territories is } \\
\text { practically not operating in Russia. } \\
\text { Currently, the Declaration of certain } \\
\text { territories as environmental disaster } \\
\text { zones does not occur, they are not } \\
\text { assigned the status of an } \\
\text { environmental disaster zone. }\end{array}$ \\
& $\begin{array}{l}\text { There is a positive experience of } \\
\text { state regulation within the } \\
\text { framework of the law of } \\
\text { Kemerovo region. }\end{array}$ & $\begin{array}{l}\text { Multi-factor operational } \\
\text { monitoring contributes to the } \\
\text { creation of a unified management } \\
\text { structure in the river basin. }\end{array}$ \\
River basin's approach & $\begin{array}{l}\text { The monitoring object is the area of } \\
\text { the reservoir's water channel and its } \\
\text { banks }\end{array}$ \\
\hline
\end{tabular}


However, to date, there is no concept of a dam territory as an object of state regulation either in Russia or in the world [3]. At the same time, the introduction of the concept of a dam area within certain borders is necessary when regulating within any model. We have given the concept of a dam territory as a territory within which this HPP has a dynamic impact. The use of the intensity of dynamic impact is possible and appropriate also because the intensity of vibrations as a key factor of the dam / surrounding geological environment clearly reflects the change in the stability of the system, even in conditions when all the components of the process are unclear.

Municipality of the urban district of Togliatti city was held the private dynamic control, allowing the tool to confirm the occurrence of vibration of residential buildings adjacent to the dam areas, the connection of vibrations of buildings with the modes of the HPP, to determine the number of buildings exposed to vibration impact, delineate the boundaries of the territory of the most intensive impacts. District of Zhigulevskaya HPP became the first, where he began a systematic study occurs when the passes through the waterworks of vibration of the soil causing a negative impact not only on the immediate territory of HPP, but also on the adjacent area around $15 \mathrm{~km}$ away. Marked the destruction of construction sites associated with the neglect of slope processes: the destruction of the embankment, destruction of retaining walls at tall buildings, deformation of buildings within the slope.

Resonant vibrations that occur in residential buildings have an impact not only on the technical condition of building structures, these vibrations are infra-gravitational, i.e. they have a specific effect on the human body. They are felt by residents at a distance of up to 5-7 $\mathrm{km}$ from the Zhigulevskaya HPP dam and exceed modern sanitary standards for vibration in residential areas. Complaints about the pitching of residential buildings have been received from residents of this territory since 1991. In this area, about 180 houses (out of 300 houses with a population of about 140 thousand people) are currently experiencing noticeable damage, which is typical for seismic load and vibration sickness of the population. Resonant vibrations that occur in residential buildings have an impact not only on the technical condition of building structures, these vibrations are infra-gravitational, i.e. they have a specific effect on the human body. They are felt by residents at a distance of up to 5-7 km from the Zhigulevskaya HPP dam and exceed modern sanitary standards for vibration in residential areas. Complaints about the pitching of residential buildings have been received from residents of this territory since 1991. In this area, about 180 houses (out of 300 houses with a population of about 140 thousand people) are currently experiencing noticeable damage, which is typical for seismic load and vibration sickness of the population.

The manifestation of dynamic influence in this area is not equivalent, its intensity gradually decreases as you move away from the dam. Based on this we can divide the area of influence of vibrations of the spillway dam:

- first level - the area directly adjacent to the waterworks up to $3 \mathrm{~km}$,

- second level-territory at a distance of $3 \mathrm{~km}$ to $7 \mathrm{~km}$,

- third level territory in the extreme limits of influence from $7 \mathrm{~km}$ to $15 \mathrm{~km}$.

The allocation of such zones, depending on the strength of the impacts, allows us to apply a variety of actions to eliminate the consequences, for making state decisions, including support for the population of these territories.

The results of experimental studies are already sufficient to start developing new regulations for the operation of dam areas. But despite the wide regional, then Federal, and now international popularity of the results of dynamic monitoring near the Zhigulevskaya hydroelectric power plant, intensive development of coastal areas continues in the same city district of Togliatti, without taking into account the dynamic impact, possible coastal deformations and activation of slope landslide processes [4]. Departmental organizations are also not in a hurry to take into account the vibration impact, for example, when predicting coastal re-formations. 
The authors consider it appropriate:

- preserve and disseminate the experience of the city district of Togliatti in controlling the dynamic impact of the hydroelectric power plant on the surrounding areas;

- do not stop the dynamic monitoring, to disseminate this method to other objects;

- initiate work to revise the regulatory framework for the procedure for taking into account the consequences of releases through the HPP to the surrounding territories; in particular, develop measures to ensure the safety of existing buildings and structures in connection with the emerging dynamic loads, new regulations for the use of coastal areas near hydroelectric facilities in general.

To illustrate the damage caused by the dynamic impact of the HPP, the cost of strengthening the Bank in the dynamic impact zone is calculated. According to our calculations, the cost of shore protection of $1 \mathrm{~m}$. p. in the area of Zhigulevskaya HPP is $1,752,048$ rubles [5]. Also, many structures require reconstruction and new construction. But all these costs pale against the background of the harm that is done to human capital. It was found, that in residential areas located on the dam areas, people suffer from various manifestations of vibration disease. In comparison with neighboring regions, the population of adjacent territories has an increased number of cardiovascular diseases, people suffer from hypertension, severe headaches, insomnia, nervous disorders, etc. The Harm caused by such exposure can be irreversible and entails serious social consequences. At the moment, it is not possible to assess the consequences of such a negative impact on the social sphere either qualitatively or quantitatively.

\section{Conclusion}

In order to ensure the safety of the dam and surrounding areas within the normal technological mode of operation of the Zhigulevskaya HPP:

- water discharge through the spillway dam is limited almost to the levels originally set by the project, including through the operation of previously unused bottom spillways into the HPP building;

- the Ministry of emergency situations of the Russian Federation has put the issue of the state and prospects of operation of the territory near the Zhigulevskaya HPP under control,

- with the involvement of Federal budget funds, certain sections of the coast have been strengthened.

On the one hand, the municipal resource has been successfully implemented, on the other hand, it has been exhausted, and Federal intervention is necessary to use the experience of a specific HPP for other large HPP where problems are manifested in a similar way.

The state can regulate this problem based on territorial, economic and security issues, including environmental ones. Each of these approaches has a multidirectional securityregulatory, financial security, and social background.

Our proposals for state regulation:

- To nominate a dam territory of a large HPP as the area of responsibility of a particular Agency.

- It is necessary to provide tax benefits for the population living in deliberately dangerous conditions (similar to an environmental disaster zone) according to the proposed zoning model

- It is necessary to consider the possibility of alienating this territory by analogy with the emergency zone. 
- Provide for the possibility of rational use of adjacent territories: for industrial use, as a tourist zone, as a zone for holding various events, designed for short-term stay, for further research.

\section{Summary}

For the first time in the world scientific literature, we propose to introduce an object of state regulation - the dam territory of the GTS - the territory within which this hydraulic structure has an intensive complex multifactorial, including dynamic impact.

Almost all dammed areas are subject to potential danger and risk to the life of the population and the economy.

No one is responsible for the safety of dam territories from dynamic impacts in Russia and in all countries of the world.

There is a need to develop operating regulations taking into account all existing factors and their interaction in the complex system that forms the GTS and the natural, social, and economic environment.

It is necessary and appropriate to zone the dam area according to the degree of dynamic impact in order to optimize administrative and economic consequences.

The work was performed according to the state task of the Institute of Water Problems of Russian Academy of Sciences, \# 0147-2019-0004, 2020.

\section{References}

1. Yu.P. Lyapichev, Hydrological and technical safety of hydraulic structures: Studies. stipend. Moscow: RUDN. p. 222. (2008)

2. V.S. Madeeva, Analysis of the legal framework for ensuring the safety of hydraulic structures // Mountain information and analytical Bulletin, Scientific and technical journal, (2014).

3. D.D. Bredlow, A.Palmieri, M. A. Salman, Regulatory framework for dam safety. Comparative-analytical review. Moscow. All the world. (2003).

4. E.M. Shumakova, Informational bases of estimation and regulation of a geoecological risks in area of HPP federal level in order to dynamic press. Proceedings of the International scientific conference «GEORISK - 2012». p. 132 (2012)

5. Guidelines for assessing the impact of hydraulic structures on the environment rd15334.2-02.409-2003 JSC, VNIIG im. B. E. Vedeneeva, Saint Petersburg (2003) 